\title{
The effect of minimal-flow and high-flow hypotensive anesthesia on oxidative stress
}

\author{
Sule Batcik ${ }^{1(\mathbb{D})}$, Leyla Kazancioglu ${ }^{1(\mathbb{D})}$, Medeni Arpa ${ }^{2(\mathbb{D})}$, İlkay Bahceci ${ }^{3(\mathbb{I D})}$, Ozcan Erel ${ }^{4(\mathbb{D})}$, \\ Salim Neselioglu 4 (ID) \\ ${ }^{1}$ Department of Anesthesiology and Reanimation, Faculty of Medicine, Recep Tayyip Erdogan University, Rize, Turkey \\ ${ }^{2}$ Faculty of Medicine, Department of Biochemistry, Recep Tayyip Erdogan University, Rize, Turkey \\ ${ }^{3}$ Faculty of Medicine, Department of Microbiology, Recep Tayyip Erdogan University, Rize, Turkey \\ ${ }^{4}$ Yildirim Beyazit University, Faculty of Medicine, Department of Biochemistry, Ankara, Turkey
}

Copyright@ Author(s) - Available online at https://dergipark.org.tr/en/pub/mbsjohs

Content of this journal is licensed under a Creative Commons Attribution-NonCommercial 4.0 International License,

Received: 12 May 2021, Accepted: 09 August 2021, Published online: 31 August 2021

(C) Ordu University Institute of Health Sciences, Turkey, 2021

\begin{abstract}
Objective: The main objective of this study was to compare the effects of minimal and high gas flowcontrolled hypotension applications on IMA and thiol/disulfide balance, which are indicators of oxidative stress.

Methods: Patients undergoing elective tympanoplasty were randomized to two groups as minimalflow and high-flow anesthesia groups. Minimal flow anesthesia was performed with $5 \mathrm{~L} / \mathrm{min}$ fresh gas flow reduced to $0.4 \mathrm{~L} / \mathrm{min}$. High flow was administered as $2 \mathrm{~L} / \mathrm{min}$ fresh gas. Preoperative and intraoperative $\mathrm{SpO} 2, \mathrm{StO} 2, \mathrm{EtCO} 2$, mean arterial pressure and heart rate values were recorded. Preoperative and intraoperative IMA, total thiol, native thiol, disulfide, disulfide/native thiol and disulfide/total thiol values were recorded and compared between the two groups.

Results: The mean intraoperative arterial pressure was statistically notably higher in the high flow group ( $\mathrm{p}=0.048$ ). The mean intraoperative SPO2 value was remarkably higher in the minimal flow group ( $\mathrm{p}=0.032$ ). The mean EtCO2 value was notably lower in the minimal flow group at 5 minutes and 15 minutes of the operation $(\mathrm{p}=0.029 ; \mathrm{p}=0.048)$. The mean preoperative and intraoperative IMA values were statistically notably higher in the minimal flow group compared to the high flow group (for both, $\mathrm{p}=0.001$ ). There was no remarkable difference between the groups in terms of the other monitored parameters (for all, $\mathrm{p}>0.05$ ).

Conclusion: IMA value was found to be significantly higher with minimal-flow anesthesia. However, no notable difference was found in terms of thiol/disulfide homeostasis, indicating the need for further comprehensive studies in order to draw a definitive conclusion.

Key words: Minimal flow, high flow, anesthetics, oxidative stress, thiols

Suggested Citation: Batcik S, Kazancioglu L, Arpa M, Bahceci I, Erel O, Neselioglu S. The effect of minimal-flow and high-flow hypotensive anesthesia on oxidative stress. Mid Blac Sea Journal of Health Sci, 2021; 7(2):221-229
\end{abstract}

Address for correspondence/reprints:

E-mail: sule.batcik@erdogan.edu.tr

Sule Batçik

Telephone number: +90 (464) 2123009 


\section{Introduction}

To be considered controlled hypotension, one must lower one'adjusted systolic or mean arterial pressure (MAP) to $50-65 \mathrm{mmHg}$, or reduce one's basal MAP by 30 percent (1). Controlled hypotension provides better visualization of surgical site during surgery, and thus decreasing blood loss, operational time and the incidence of complications (2). Some studies have proposed that decreased platelet activity during hypotension protects against postoperative consumptive coagulopathy (3). Numerous agents can be used for controlled hypotension including direct vasodilators, beta blockers, alpha blockers, and combined alpha-beta blockers. The ideal agent to be used for this purpose should be easily applied with dose-dependent effects, rapid onset and minimal side effects (1). On the other hand, hypotensive anesthesia is associated with decreased perfusion to vital organs such as the brain, heart and kidneys. Therefore, when performing hypotension contraindications such as cerebrovascular disease, liver dysfunction and renal dysfunction that suggest low organ perfusion in the patient should be taken into account (4). In addition, general anesthetic agents, postoperative analgesic regimen and anesthesia-induced hypotension may lead to oxidative stress related to surgical stress.

The imbalance between reactive oxygen species (ROS) and antioxidant defense mechanisms is referred to as oxidative stress (OS). OS is involved in ageing, inflammation, cancer and expose to drugs such as anesthetic agents. Contribution of anesthetic procedures to surgical stress and postoperative complication has been associated with increased oxidative stress and release of inflammatory cytokines (5). Anesthesia-induced oxidative stress may affect proteins, lipids and DNA. Surgical patients can undergo surgeries that may cause inflammation, surgical trauma, and ischemiareperfusion injury all of which are resulted from oxidative stress (6).

Anesthesia can be performed with both minimal and high fresh gas flow. Minimal gas flow $(\leq 0.5$ $\mathrm{L} / \mathrm{min}$ ) has several advantages. These include reduction in the use of inhalational anesthetics, improved body temperature and humidity homeostasis, decreased environmental pollution and significance cost saving (7). However, high gas flow between $2 \mathrm{~L} / \mathrm{min}$ and $6 \mathrm{~L} / \mathrm{min}$ is still being used. Both methods have specific advantages and disadvantages. Controlled anesthetic hypotension applications with these two forms of flow were thought to have different effects on oxidative stress parameters. There is no study on the literature on this subject. Therefore, the purpose of this research was to compare the effects of minimal and high gas flow-controlled hypotension applications on IMA and thiol/disulfide balance, which are indicators of oxidative stress.

\section{Methods}

A number of 89 patients aged between 18-60 years with an American Society of Anesthesiologists (ASA) status I or II, who underwent elective tympanoplasty operation under hypotensive anesthesia between August 2018 and December 2018 were participated in the study. Three patients were excluded from the study because their blood samples were coagulated and two patients since they developed hypotension that required short-term inotropic support, and finally the study was completed with 84 patients. Patients with uncontrolled hypertension, diabetes mellitus, cerebrovascular disease, morbid obesity (BMI $\geq 35$ $\mathrm{Kg} / \mathrm{m} 2$ ), anemia, pregnancy, renal disease, carotid artery stenosis and those who used antioxidant drugs, smokers, and patients with alcohol and drug addiction were excluded from the study. All operations were performed by the same otorhinology surgical team.

Patients were randomly assigned to one of two groups. In the group to be administered minimal flow anesthesia Group MF, a fresh gas flow of $5 \mathrm{~L} / \mathrm{min}$ (50\% oxygen and 50\% air) was provided for 10 minutes following intubation. After the tenth minute, oxygen support was provided so that the inspiratory oxygen fraction (FiO2) would not fall below $50 \%$ and the fresh gas flow was reduced to $0.4 \mathrm{~L} / \mathrm{min}$. Whereas in the high flow anesthesia group (Group HF) was administered $2 \mathrm{~L} / \mathrm{min}$ fresh gas flow $(50 \%$ oxygen, $50 \%$ air) continuously.

\section{Monitoring and Anesthesia Management}

The same perioperative monitoring procedure was applied in all patients. A 20-gauge intravenous (iv) cannula was placed on the dorsum of the left hand of the patients 30 minutes before the operation and 5 $\mathrm{mL} / \mathrm{Kg}$ isotonic fluid was given. Venous blood samples were collected via an 18 Gauge iv cannula inserted into the right brachial vein.

All patients were followed-up with routine monitoring including three-derivation electrocardiogram (ECG), peripheral oxygen saturation $(\mathrm{SpO} 2)$ and non-invasive arterial blood pressure. Evaluation of anesthesia depth and sedation was analyzed by bispectral index (BIS) using the mean frequency of electroencephalography (EEG). BIS provides conversion of the EEG recording to integers in the range of 1-100, and its value decreases as anesthesia deepens. Values of BIS between 40 and 60 indicate the appropriate depth of anesthesia. With 
BIS monitoring, the control of the depth of anesthesia becomes objective (8). The bispectral index was also measured with an electrode with four leads placed on the patient's forehead. (Covidien, Boulder, $\mathrm{CO}$, USA). Peripheral tissue oxygen saturation ( $\mathrm{StO} 2)$ was monitored via a probe inserted to the thenar region of the left hand through InSpectraTM StO2 Spot Check Model 3000 (Hutchinson Technology, INC., Hutchinson, MN, USA) device, which measures with NIRS technology. In all patients, Dräger Primus (Dräger Medical, Lübeck, Germany) was used as the anesthesia device and CLIC Absorber $800+$ (Dräger Medical, Lübeck, Germany) as the soda lime. All patients were received $0.02 \mathrm{mg} / \mathrm{Kg}$ iv midazolam as premedication and preoxygenation was applied with 5L/min $100 \%$ oxygen. For induction, 1 $\mu \mathrm{g} / \mathrm{Kg}$ iv remifentanil was administered over 60 seconds as the loading dose followed by $1 \mathrm{mg} / \mathrm{Kg}$ iv lidocaine ve $2 \mathrm{mg} / \mathrm{Kg}$ iv propofol. Neuromuscular block was provided with $0.6 \mathrm{mg} / \mathrm{Kg}$ iv rocuronium bromide. In the maintenance of anesthesia, desflurane and $0.25-0.75 \mu \mathrm{g} / \mathrm{Kg} / \mathrm{min}$ iv remifentanil was used. The BIS value was maintained between $40 \%$ and $60 \%$. Following endotracheal intubation, $6 \mathrm{ml} / \mathrm{Kg}$ tidal volume and $5 \mathrm{~cm} \mathrm{H} 2 \mathrm{O}$ positive end-expiratory pressure were applied according to the ideal body weight in volume-controlled mode with the Dräger Primus anesthesia device. Respiratory frequency was adjusted to be in the range of EtCO2 35-40.

Controlled hypotension was achieved in patients by reducing the MAP by $30 \%$ from the baseline value or by maintaining it to be $60-65 \mathrm{mmHg}$ during the operation. A mean arterial pressure $<50 \mathrm{mmHg}$ was considered as hypotension, a HR $<45 \mathrm{bpm}$ as bradicardia, and remifentanil infusion was stopped, and ephedrine $(5 \mathrm{mg})$ and atropine $(0.5 \mathrm{mg})$ doses were added for the treatment.

Fifteen minutes before the end of the surgery, 100 mg iv tramadol was administered for postoperative analgesia and $8 \mathrm{mg}$ iv ondansetron for antiemetic purposes. When it was reported that there was 10 minutes to the end of the surgery, the fresh gas flow was increased to $5 \mathrm{~L} / \mathrm{min}$ and desflurane was discontinued in both groups. $100 \%$ oxygen support was initiated. Infusion rate of remifentanil was lowered to $0.2 \mu \mathrm{g} / \mathrm{Kg}$. When the BIS value exceeded $80 \%$ and the patient began to obey verbal commands, $15 \mu \mathrm{g} / \mathrm{kg}$ iv atropine and $50 \mu \mathrm{g} / \mathrm{kg}$ iv neostigmine was administered and extubation was performed. All patients were taken to the postoperative recovery room. If the Aldrete score was 9-10, the patient was sent to the service.

\section{Data Collection}

$\mathrm{EtCO} 2$, inspiratory oxygen fraction (FiO2), inspiratory desflurane fraction (FiDESF) values were measured and recorded before anesthesia induction, at 5-, 15-, 30- and 60-minutes following intubation. The heart rate (HR), mean arterial blood pressure (MAP), $\mathrm{SpO} 2$ and $\mathrm{StO} 2$ values were recorded 10 minutes before the induction of anesthesia and at 60 minutes of the operation.

\section{Biochemical Analysis}

Ten minutes before the induction of anesthesia and at 60 minutes of the operation, 2 milliliters of venous blood samples were taken into biochemistry tubes containing coded anticoagulant and serum separator, centrifuged at $1500 \mathrm{rpm}$ for 10 minutes and stored frozen at $-80^{\circ} \mathrm{C}$. The spectrophotometric was used to measure the thiol/disulfide homeostasis which method developed by Erel and Neselioglu (9). This was accomplished by first reducing disulfide bonds in order to produce free functional thiol groups that included sodium borohydride. The unused reducing sodium borohydride was depleted with formaldehyde to prevent reduction of 5,5'-dithiobis- (2nitrobenzoic) acid (DTNB). After reaction with DTNB, all thiol groups including the reduced "disulfide", "native thiol" and "total thiol" groups were determined. Following the determination of native and total thiols, the amounts of disulfide were calculated as Disulfide/native Thiol ratio, Disulfide/Total thiol ratio and Native thiol/Total thiol ratio.

IMA levels were determined with the rapid colorimetric method developed by Bar-Or et al. using an autoanalyzer (Mindray BS 2000, Mindray BioMedical Electronics Co. Ltd., Shenzhen, China) (10). In brief, $200 \mu \mathrm{L}$ patient serum was added to $50 \mu \mathrm{L} 1$ $\mathrm{g} / \mathrm{L}$ cobalt chloride solution and after mixing vigorously, the mixture was left in the dark incubation for 10 minutes. Then, $50 \mu \mathrm{L}$ dithiothreitol (DTT; 1.5 $\mathrm{g} / \mathrm{L}$ ) was added and mixed. After incubation for 2 minutes, $1 \mathrm{~mL}$ was added to $9 \mathrm{~g} / \mathrm{L} \mathrm{NaCl}$ solution. The absorbance of test mixtures was read at $470 \mathrm{~nm}$ and the results were calculated as the absorbance unit (AU).

\section{Ethics Considerations}

Before the beginning, the necessary approval was received from the Non-interventional Clinical Research Ethics Committee of our hospital with the 2018/64 decision. All patients gave written consent, and the study was conducted in line with the ethical principles of the Declaration of Helsinki. 


\section{Statistical Analysis}

For statistical analysis of data, NCSS (Number Cruncher Statistical System) 2007 (Kaysville, Utah, USA) software was used. Descriptive statistics (mean \pm standard deviation, minimum, maximum) were used to express the results. Normality of the variables was tested with the Shapiro-Wilk method. To compare normally distributed quantitative variables across three or more time periods, the Repeated Measure test was used. The Friedman test was used for the comparison of non-normally distributed quantitative variables between three or more periods. The Mann-Whitney U test was used for comparing non-normally distributed qualitative variables between two groups. The student t test was used for the comparison of normally distributed qualitative variables between two groups. $\mathrm{p}<0.05$ values were considered statistically significant.

\section{Results}

Of all patients included in the study, 38 (45.2\%) were female and $35(54.8 \%)$ were male. The patients aged between 18-60 years with a mean age of $32.96 \pm 13.09$ years. The mean body mass index (BMI) was calculated as 24.61 \pm 3.94 (min-max: 16.61-34.25) $\mathrm{Kg} / \mathrm{m} 2$. Forty-six patients $(53.6 \%)$ were in the minimal flow (MF) group and $39(46.4 \%)$ in the high flow (HF) group.

When routine anesthetic monitoring parameters were evaluated; the mean preoperative tissue hemoglobin index (THI) value was $10.56 \pm 1.67$ in Group MF, while this value was $12.09 \pm 2.33$ in Group HF. The difference between two groups in terms of preoperative THI was significant $(p=0.003)$. The mean intraoperative arterial pressure was statistically significantly higher in Group HF (63.72 \pm 4.59$)$ compared to Group MF $(61.53 \pm 4.87)(\mathrm{p}=0.048)$. The mean intraoperative $\mathrm{SpO} 2$ value was $98.49 \pm 1.16$ in Group MF and $99.03 \pm 1.09$ in Group HF. The difference between both groups was statistically notable $(\mathrm{p}=0.032)$. However, hypoxia was not observed in any patient. No statistically notable difference was found between the two groups in terms of the BIS parameters followed in the intraoperative period $(p>0.05)$. No statistically significant difference was found between the two groups in terms of the other monitored parameters (for all $\mathrm{p}>0.05$ ). Comparison of the routinely monitored parameters between the groups is given in Table 1 .

When intraoperative anesthesia monitoring data were examined; the mean $\mathrm{EtCO} 2$ value was significantly lower in Group MF at 5 minutes $(32.73 \pm 3.12$ vs $34.33 \pm 3.49)$ and 15 minutes $(31.16 \pm 5.68$ vs $33.31 \pm 3.78)$ compared to Group HF $(p=0.029$ and
Table 1. Anesthesia monitoring parameters according to the groups

\begin{tabular}{|c|c|c|c|c|}
\hline Parameter & Group & Mean \pm SD & $\begin{array}{l}\text { Min- } \\
\text { Max }\end{array}$ & $\mathbf{p}$ \\
\hline Preoperative & MF & $77.31 \pm 7.94$ & $55-93$ & \multirow{2}{*}{${ }^{\mathrm{a}} 0.602$} \\
\hline $\mathrm{StO}_{2}$ & HF & $78.08 \pm 6.76$ & $63-91$ & \\
\hline Intraoperative & MF & $87.82 \pm 6.37$ & $63-95$ & \multirow{2}{*}{ b 0.227} \\
\hline $\mathrm{StO}_{2}$ & HF & $86.15 \pm 6.15$ & $75-97$ & \\
\hline Preoperative & MF & $10.56 \pm 1.67$ & $7.3-13.8$ & \multirow[b]{2}{*}{${ }^{\text {a }} 0.003 * *$} \\
\hline THI & HF & $12.09 \pm 2.33$ & $7.1-17.2$ & \\
\hline Intraoperative & MF & $11.71 \pm 2.03$ & $8.2-16.3$ & \multirow[b]{2}{*}{ a 0.067} \\
\hline THI & HF & $12.46 \pm 2.26$ & $7-16.6$ & \\
\hline Preoperative & MF & $\begin{array}{c}85.38 \pm 14.6 \\
4\end{array}$ & $52-120$ & \multirow{2}{*}{ a 0.753} \\
\hline HR & HF & $\begin{array}{c}83.28 \pm 13.1 \\
1\end{array}$ & $48-110$ & \\
\hline Intraoperative & MF & $\begin{array}{c}64.67 \pm 10.6 \\
1\end{array}$ & $51-96$ & \multirow{2}{*}{${ }^{\mathrm{b}} 0.388$} \\
\hline HR & HF & $62.82 \pm 8.59$ & $48-88$ & \\
\hline Preoperative & MF & $\begin{array}{c}91.27 \pm 12.6 \\
6\end{array}$ & $56-120$ & \multirow{2}{*}{ a 0.943} \\
\hline MAP & HF & $\begin{array}{c}90.46 \pm 11.7 \\
4 \\
\end{array}$ & $59-112$ & \\
\hline Intraoperative & MF & $61.53 \pm 4.87$ & $51-72$ & \multirow{2}{*}{${ }^{\mathrm{a}} 0.048 *$} \\
\hline MAP & HF & $63.72 \pm 4.59$ & $55-76$ & \\
\hline Preoperative & MF & $98.96 \pm 1.3$ & $95-100$ & \multirow{2}{*}{ b 0.293} \\
\hline $\mathrm{SPO}_{2}$ & HF & $98.54 \pm 2.25$ & $90-100$ & \\
\hline Intraoperative & MF & $98.49 \pm 1.16$ & $95-100$ & \multirow[t]{2}{*}{${ }^{\mathrm{b}} 0.032 *$} \\
\hline $\mathrm{SPO}_{2}$ & HF & $99.03 \pm 1.09$ & $95-100$ & \\
\hline
\end{tabular}

Abbreviations: $\mathrm{StO}_{2}$ : tissue oxygen saturation; THI: tissue hemoglobin index: HR: heart rate; MAP: mean arterial pressure; $\mathrm{SpO}_{2}$ : oxygen saturation, Mann Whitney Testi (a). Student $\mathrm{T}$ Testi (b) $\quad * \mathrm{p}<0.05 \quad * * \mathrm{p}<0.01$

$\mathrm{p}=0.048$; respectively). The mean $\mathrm{FiO} 2$ value was significantly higher in Group MF at 5 minutes $(68.36 \pm 18.37$ vs $53.44 \pm 11.94)$ and 15 minutes $(53.76 \pm 15.08$ vs $42.69 \pm 8.12)$ compared to Group HF (for both $\mathrm{p}=0.001$ ). The mean FiDESF value was statistically remarkably higher in Group MF (6.07 \pm 1.22$)$ compared to Group HF $(4.94 \pm 1.24)$ at intraoperative 5 minutes $(\mathrm{p}=0.001)$. The mean FiDESF value was statistically significantly lower in

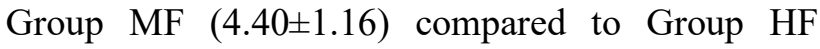
$(5.13 \pm 1.12)$ at intraoperative 30 minutes $(\mathrm{p}=0.004)$. No statistically notable difference was observed 
between both groups in terms of the other monitored intraoperative parameters (for all p>0.05) (Table 2).

Table 2. Intraoperative anesthetic parameters according to the groups

\begin{tabular}{|c|c|c|c|c|}
\hline & & Mean \pm SD & $\begin{array}{l}\text { Min- } \\
\text { Max }\end{array}$ & $\mathbf{p}$ \\
\hline 5 minutes & MF & $32.73 \pm 3.12$ & $23-38$ & \multirow{2}{*}{${ }^{\mathrm{b}} \mathbf{0 . 0 2 9} *$} \\
\hline $\mathrm{EtCO}_{2}$ & $\mathbf{H F}$ & $34.33 \pm 3.49$ & $28-42$ & \\
\hline 15 minutes & MF & $31.16 \pm 5.68$ & $0-39$ & \multirow{2}{*}{${ }^{\mathrm{b}} 0.048^{*}$} \\
\hline $\mathrm{EtCO}_{2}$ & $\mathbf{H F}$ & $33.31 \pm 3.78$ & $21-41$ & \\
\hline 30 minutes & MF & $31.87 \pm 3.56$ & $23-44$ & \multirow{2}{*}{ b 0.495} \\
\hline $\mathrm{EtCO}_{2}$ & HF & $32.36 \pm 2.92$ & $26-38$ & \\
\hline 60 minutes & MF & $31.93 \pm 4.06$ & $24-48$ & \multirow{2}{*}{ b 0.483} \\
\hline $\mathrm{EtCO}_{2}$ & $\mathbf{H F}$ & $32.46 \pm 2.5$ & $27-38$ & \\
\hline 5 minutes & MF & $68.36 \pm 18.37$ & $36-93$ & \multirow{2}{*}{${ }^{\mathrm{b}} 0.001 * *$} \\
\hline $\mathrm{FiO}_{2}$ & HF & $53.44 \pm 11.94$ & $32-87$ & \\
\hline 15 minutes & MF & $53.76 \pm 15.08$ & $29-88$ & \multirow{2}{*}{${ }^{\mathrm{b}} 0.001 * *$} \\
\hline $\mathrm{FiO}_{2}$ & HF & $42.69 \pm 8.12$ & $33-72$ & \\
\hline 30 minutes & MF & $41.07 \pm 8.72$ & $29-66$ & \multirow{2}{*}{${ }^{\mathrm{b}} 0.078$} \\
\hline $\mathrm{FiO}_{2}$ & HF & $38.13 \pm 5.86$ & $31-55$ & \\
\hline 60 minutes & MF & $35.91 \pm 6.49$ & $29-55$ & \multirow{2}{*}{ b 0.349} \\
\hline $\mathrm{FiO}_{2}$ & HF & $37.13 \pm 5.16$ & $30-55$ & \\
\hline 5 minutes & MF & $6.07 \pm 1.22$ & $2.4-8.1$ & \multirow[b]{2}{*}{${ }^{\mathrm{a}} 0.001 * *$} \\
\hline FiDESF & HF & $4.94 \pm 1.24$ & $2.1-7.8$ & \\
\hline 15 minutes & MF & $5.15 \pm 1.53$ & $\begin{array}{c}1.06 .200 \\
9\end{array}$ & \multirow{2}{*}{${ }^{\mathrm{a}} 0.557$} \\
\hline FiDESF & HF & $4.91 \pm 1.17$ & $\begin{array}{c}2.07 .200 \\
8 \\
\end{array}$ & \\
\hline 30 minutes & MF & $4.4 \pm 1.16$ & $1.4-6.4$ & \multirow[b]{2}{*}{${ }^{\mathrm{b}} 0.004 * *$} \\
\hline FiDESF & HF & $5.13 \pm 1.12$ & $\begin{array}{c}2.07 .200 \\
4\end{array}$ & \\
\hline 60 minutes & MF & $4.58 \pm 1.29$ & $1.7-6.9$ & \multirow[b]{2}{*}{${ }^{\mathrm{b}} 0.145$} \\
\hline FiDESF & HF & $4.96 \pm 1.01$ & $\begin{array}{c}2.07 .200 \\
1\end{array}$ & \\
\hline
\end{tabular}

Abbreviations: EtCO2: end tidal carbon dioxide; FiO2: fraction of inspired oxygen; FiDESF: fraction of inspired desflurane, Mann Whitney Testi (a). Student T Testi (b) $\quad * \mathrm{p}<0.05 \quad * * \mathrm{p}<0.01$
Table 3. Preoperative and intraoperative oxidative stress parameters of the groups

\begin{tabular}{|c|c|c|c|c|}
\hline & & $\operatorname{Mean} \pm$ SD & Min-Max & $p$ \\
\hline \multirow{2}{*}{ Albumin } & MF & $4.83 \pm 0.13$ & $4.49-5.03$ & \multirow{2}{*}{${ }^{a} 0.637$} \\
\hline & HF & $4.84 \pm 0.13$ & $4.58-5.09$ & \\
\hline \multirow{2}{*}{$\begin{array}{l}\text { Ischemia } \\
\text { Modified } \\
\text { Albumin } 1\end{array}$} & MF & $0.74 \pm 0.08$ & $0.56-0.97$ & \multirow{2}{*}{$\begin{array}{c}a \\
0.001 * *\end{array}$} \\
\hline & HF & $0.58 \pm 0.09$ & $0.4-0.82$ & \\
\hline \multirow{3}{*}{ Native Thiol 1} & MF & $343.66 \pm 52.18$ & $249.9-475.4$ & \multirow{3}{*}{${ }^{a} 0.360$} \\
\hline & & & & \\
\hline & $\mathbf{H F}$ & $330.48 \pm 51.6$ & 206.7-432.9 & \\
\hline \multirow[t]{2}{*}{ Total Thiol 1} & MF & $385.81 \pm 54.56$ & $288.79-516.29$ & \multirow[t]{2}{*}{${ }^{a} 0.358$} \\
\hline & HF & $370.58 \pm 54.99$ & $240.6-484.5$ & \\
\hline \multirow{3}{*}{ Disulfide 1} & MF & $21.07 \pm 4.07$ & $11.56-32.2$ & \multirow{3}{*}{${ }^{a} 0.177$} \\
\hline & & & & \\
\hline & HF & $20.05 \pm 3.8$ & $10.5-28.55$ & \\
\hline $\begin{array}{l}\text { Disulfide } \\
\text { Native }\end{array}$ & MF & $6.23 \pm 1.33$ & $3.02-9.12$ & \multirow{2}{*}{${ }^{b} 0.784$} \\
\hline Thiol 1 & $\mathbf{H F}$ & $6.15 \pm 1.31$ & $4.06-11.14$ & \\
\hline $\begin{array}{l}\text { Disulfide } \\
\text { Total }\end{array}$ & MF & $5.52 \pm 1.05$ & $2.85-7.71$ & \multirow{2}{*}{${ }^{a} 0.518$} \\
\hline Thiol 1 & $\mathbf{H F}$ & $5.46 \pm 1.01$ & $3.76-9.11$ & \\
\hline Native Thiol / & MF & $88.97 \pm 2.1$ & $84.58-94.3$ & \multirow[b]{2}{*}{${ }^{a} 0.510$} \\
\hline Total Thiol 1 & $\mathbf{H F}$ & $89.09 \pm 2.02$ & $81.77-92.49$ & \\
\hline \multirow{3}{*}{ Albumin 2} & MF & $4.69 \pm 0.13$ & $4.43-4.96$ & \multirow{3}{*}{${ }^{a} 0.939$} \\
\hline & & & & \\
\hline & HF & $4.69 \pm 0.16$ & $4.31-4.96$ & \\
\hline $\begin{array}{l}\text { Ischemia } \\
\text { Modified }\end{array}$ & MF & $0.9 \pm 0.12$ & $0.66-1.4$ & $a$ \\
\hline Albumin 2 & $\mathbf{H F}$ & $0.72 \pm 0.13$ & $0.51-1$ & $0.001 * *$ \\
\hline \multirow{3}{*}{ Native Thiol 2} & MF & $255.62 \pm 56.14$ & $125.6-376.9$ & \multirow{3}{*}{${ }^{a} 0.979$} \\
\hline & & & & \\
\hline & $\mathbf{H F}$ & $252.48 \pm 63.33$ & $79.4-342.7$ & \\
\hline \multirow[t]{2}{*}{ Total Thiol 2} & MF & $296.5 \pm 56.48$ & $166.51-412.29$ & \multirow[t]{2}{*}{${ }^{a} 0.600$} \\
\hline & HF & $289.68 \pm 61.02$ & 138.5-386.2 & \\
\hline \multirow[t]{2}{*}{ Disulfide 2} & MF & $20.44 \pm 6.43$ & $12.71-49.49$ & \multirow[t]{2}{*}{${ }^{b} 0.162$} \\
\hline & HF & $18.6 \pm 5.34$ & $12.75-38.45$ & \\
\hline $\begin{array}{l}\text { Disulfide/ } \\
\text { Native }\end{array}$ & MF & $8.58 \pm 5.15$ & $4.35-39.4$ & \multirow[t]{2}{*}{${ }^{b} 0.943$} \\
\hline Thiol 2 & HF & $8.49 \pm 6.53$ & $4.49-37.22$ & \\
\hline $\begin{array}{l}\text { Disulfide } \\
\text { /Total }\end{array}$ & MF & $7.09 \pm 2.75$ & $4-22.04$ & \multirow[t]{2}{*}{${ }^{b} 0.753$} \\
\hline Thiol 2 & HF & $6.87 \pm 3.57$ & $4.12-21.34$ & \\
\hline Native Thiol / & MF & $85.82 \pm 5.5$ & $55.93-91.99$ & \multirow{2}{*}{${ }^{b} 0.754$} \\
\hline Total Thiol 2 & HF & $86.26 \pm 7.13$ & $57.33-91.76$ & \\
\hline
\end{tabular}


Figure 1 presents a visual depiction of the intraoperatively monitored anesthetic parameters. Oxidative stress parameters were compared between Group MF and Group HF in the preoperative and intraoperative periods. Accordingly, there was a statistically notable difference between the groups in terms of the preoperative and intraoperative ischemia modified albumin (IMA). The mean preoperative IMA value was statistically significantly higher in Group MF $(0.74 \pm 0.008)$ compared to Group HF $(0.58 \pm 0.09) \quad(p=0.001)$. Similarly, the mean intraoperative IMA value was statistically remarkably higher in Group MF $(0.90 \pm 0.12)$ compared to Group HF $(0.72 \pm 0.13)(\mathrm{p}=0.001)$. In Group MF, the mean IMA value increased by $21.6 \%$ at intraoperative 60 minutes compared to the baseline value, while this rate was $24.1 \%$ in Group HF. No statistically remarkable difference was found between the two groups in terms of the mean total thiol, native thiol, disulfide, disulfide/native thiol, disulfide/total thiol and native thiol/total thiol values both in the preoperative and intraoperative periods (for all $\mathrm{p}>0.05$ ). Table 3 shows oxidative stress parameters of both groups and Table 4 shows the changes in oxidative stress parameters.

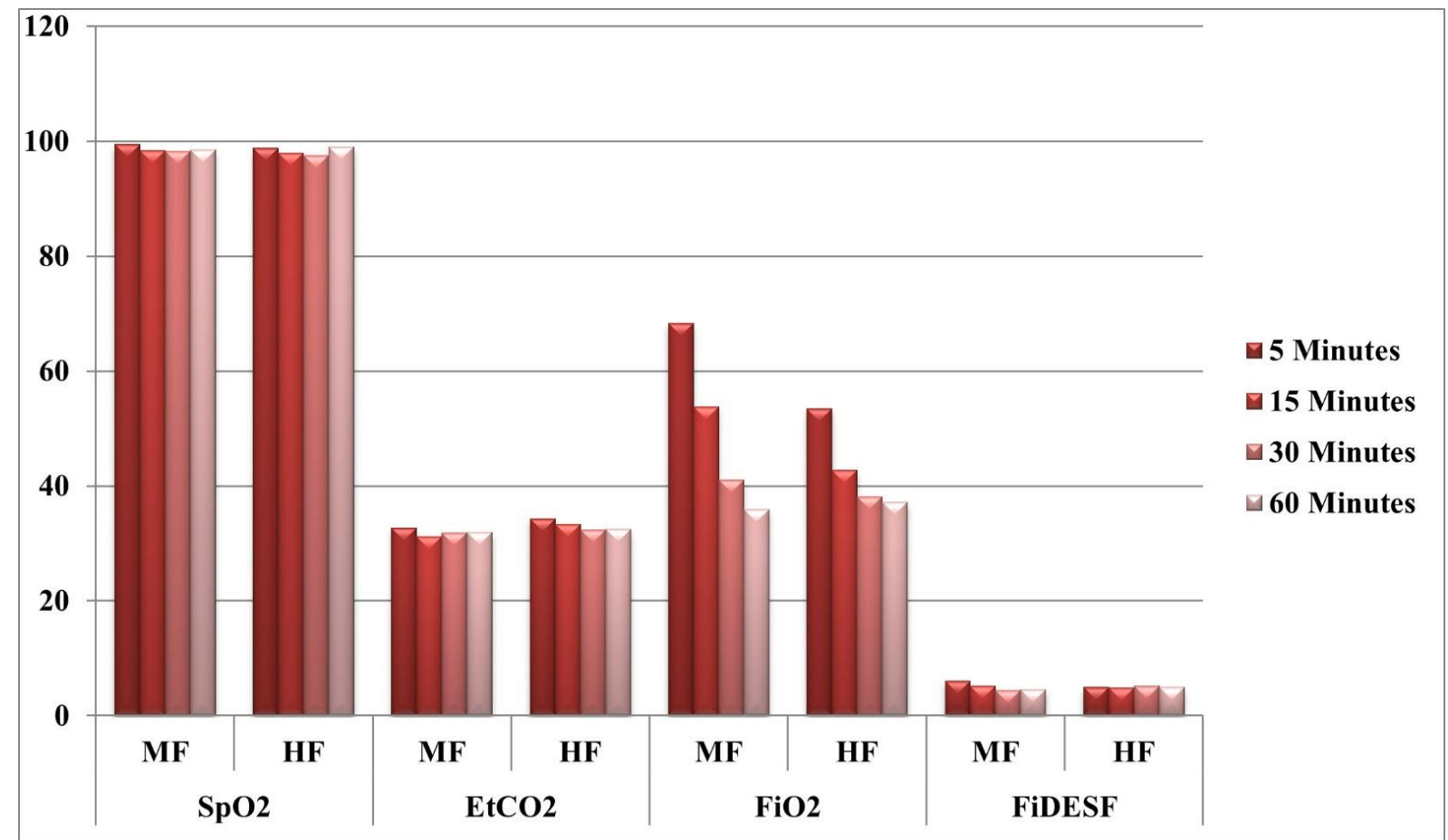

Figure 1. Changes in the monitored anesthetic parameters in the intraoperative period

Table 4. The changes in the oxidative stress parameters according to the groups (\%)

Minimal Flow

High Flow

\begin{tabular}{lcccccc}
\multicolumn{1}{r}{} & Pre-op & Intra-op & Change $(\%)$ & Pre-op & Intra-op & Change (\%) \\
\hline IMA & 0.74 & 0.9 & 21.62 & 0.58 & 0.72 & 24.14 \\
NT & 443.66 & 255.62 & -42.38 & 330.48 & 252.48 & -23.60 \\
TT & 385.81 & 296.5 & -23.15 & 370.58 & 289.68 & -21.83 \\
DIS & 21.07 & 20.44 & -2.99 & 20.05 & 18.6 & -7.23 \\
DIS/NT & 6.23 & 8.58 & 37.72 & 6.15 & 8.49 & 38.05 \\
DIS/TT & 5.52 & 7.09 & 28.44 & 5.46 & 6.87 & 25.82 \\
NT/TT & 88.97 & 85.82 & -3.54 & 89.09 & 86.26 & -3.18 \\
\hline
\end{tabular}

Abbreviations: IMA: ischemia modified albumin; NT: native thiol; TT: total thiol; DIS: disulfide 


\section{Discussion}

Controlled hypotension is defined as keeping systolic blood pressure in the range of $80-90 \mathrm{mmHg}$ or mean arterial pressure (MAP) in the range of 50$65 \mathrm{mmHg}(1,11)$. Intravenous anesthetics, inhalation anesthetics, opioids, calcium channel blockers, beta blockers and nitrate derivatives are often used for this purpose (12). Pharmacokinetic and pharmacodynamic properties of these agents are quite different. Anesthetic agents used for hypotensive anesthesia are known to have effects on oxidantantioxidant balance of the body, and thus oxidative stress. Anesthesia-induced oxidative stress may affect lipids, proteins and DNA (13). Therefore, it is important to determine oxidative stress induced by anesthetic stress in individuals who are exposed to anesthetic agents for a long time or to anesthesia applications. Both duration and nature of the anesthetic procedures may affect the degree of oxidative stress (13).

In our study, in the anesthetic management of the patients undergoing tympanoplasty, controlled hypotension was provided by keeping MAP in the range of 51-76 mmHG. Respiratory frequency was adjusted to be in the range of EtCO2 35-40. Anesthetic management was performed with remifentanil loading dose followed by lidocaine and propofol as intravenous agents. Anesthesia maintenance was provided by desflurane as the inhalation anesthetic and remifentanil as the intravenous agent.

Safety of anesthetics has drawn attention in terms of toxicity and potential side effects for a long time (14). Inhalation of volatile anesthetics mechanical ventilation triggers an inflammatory response, which increases systemic oxidative stress, impairing oxidant-antioxidant balance. Multiple chronic diseases such as neurodegenerative diseases, cardiovascular diseases, and cancer are caused by oxidative stress accumulation $(15,16)$.

The effects of desflurane, which was used as the inhalation agent, and propofol, which was used as the intravenous agent in our study have been investigated in several studies. Intravenous anesthetics including propofol directly remove reactive oxygen species (ROS) and inhibit lipid peroxidation (17). On the contrary, inhalation anesthetics such as desflurane have been shown to produce ROS (18). In an animal study by Allaouchiche et al., it was reported that the concentrations of MDA, one of the oxidative stress markers, and consumption of GPx, which is among the antioxidant defenses, were increased in both serum and lavage samples of the pigs exposed to desflurane. Conversely, MDA levels and the consumption of GPx were decreased in the animals exposed to propofol (19). Thus, the authors demonstrated the presence of local and systemic oxidative stress in mechanically ventilated animals during desflurane exposure. One of the factors that may be responsible for desflurane anesthesia related oxidative stress is the increase in the expression of proinflammatory cytokines in macrophages (20). Propofol has similar chemical properties with alphatocopherol, which is an endogenous antioxidant.

General anesthesia performed to create controlled hypotension can be performed with minimal and high fresh gas flow. Minimal flow anesthesia is considered as a subtype of low flow anesthesia with the lowest possible volume and full rebreathing. This method can be performed safely with modern anesthesia devices (21). Desflurane has a low blood/gas solubility and is preferred as an ideal and safe inhalation anesthetic for minimal-flow anesthesia. In a study by Ceylan et al., considering hemodynamic data, minimal-flow anesthesia technique was reported to be a hemodynamically safe and stable method (22). Some advantages of minimal-flow anesthesia include less impairment of pulmonary function, better protection of the respiratory system, reduced cost and decreased environmental pollution (23).

In our study, we observed the effects of minimal flow and high flow anesthesia on anesthesia monitoring parameters and oxidative stress. In this study, the difference between the intraoperative SPO2 values at 5,15 and 30 minutes was not significant, but the 60-minute SPO2 values were notably lower in the minimal flow group $(98.49 \%)$ compared to the high flow group $(99.03 \%)$. Kilic et al. In the study performed by Abdominal surgery, the difference between intraoperative SPO2 values reached a significant level at the 45th minute of the operation and the mean SPO2 value was found to be 98.85 in the low flow group and $99.40 \%$ in the high flow group (24). The results of these two studies support each other.

IMA has been shown to increase as a result of oxidative stress (25). Changes in the binding capacity of albumin to transit metals as a result of oxidative stress during ischemia/reperfusion lead to the formation of IMA $(10,26)$. In our study, we compared the effects of minimal and high flow anesthesia techniques on oxidative stress through IMA. In our study, the mean intraoperative IMA value was notably higher in the minimal flow group compared to the high flow group. However, the change in the IMA values was higher in the high-flow group. 
In cells, sulfhydryl group-containing chemical compounds such as thiol play a critical function in the protection of oxidative stress (27). Between thiols and their oxidized forms, disulfides, there is a balance known as dynamic thiol/disulfide homeostasis. Increased disulfide/native thiol and disulfide/total thiol ratios in favour of disulfide can be considered as an indicator of oxidative stress. In our study, native and total thiol values were decreased in both minimal flow and high flow groups. However, the decreases in intraoperative native thiol and total thiol values were higher than the decrease in disulfide values in both groups. This indicates oxidative stress with both flow techniques, but no notable difference was found between the groups in terms of thiol/disulphide homeostasis.

\section{Study Limitations}

This study has many limitations. First, it was conducted in a single center with a relatively small number of patients. Second, we could not directly compare our results since there was no study in the literature comparing minimal and high flow techniques in terms of oxidative stress parameters. Finally, different oxidative stress parameters could be included in the study. However, this is the first study in the literature investigating the effects of different flow techniques on oxidative stress, and we think that our results will guide future studies.

\section{Conclusion}

There was no significant difference was found between minimal-flow and high-flow anesthesia techniques in terms of their effects on oxidative stress. Only IMA values were higher with minimalflow anesthesia. However, since no notable difference was found in terms of thiol/disulfide homeostasis, evaluation of IMA alone may not be meaningful. This subject is relatively new in the literature, and further comprehensive prospective studies are needed on this subject.
Ethics Committee Approval: Ethics committee approval was obtained from Clinical Research and Ethics Committee (Report no: 2018/64).

Peer-review: Externally peer-reviewed.

\section{Author Contributions:}

Concept: S.B, L.K, Design: S.B, L.K; Literature search: S.B, L.K, M.A, I.B, O.E, S.N, Data Collection and Processing: M.A, I.B, O.E, S.N, Analysis or Interpretation: M.A, I.B, O.E, S.N, Writing: S.B, L.K, M.A, I.B, O.E, S.N

Conflict of Interest: No conflict of interest was declared by the authors.

Financial Disclosure: The authors declared that this study hasn't received no financial support.

\section{References}

1. Degoute CS. Controlled hypotension: a guide to drug choice. Drugs. 2007;67(7):1053-1076.

2. Stammberger H, Posawetz W. Functional endoscopic sinus surgery. Concept, indications and results of the Messerklinger technique. Eur Arch Otorhinolaryngol. 1990;247(2):63-76.

3. Felfernig-Boehm D, Salat A, Kinstner C, et al. Influence of hypotensive and normotensive anesthesia on platelet aggregability and hemostatic markers in orthognathic surgery. Thromb Res. 2001;103(3):185-192.

4. Sanad HA, Mohamed AZ, Abd-elraouf AA. Comparative study between three Different Doses of Magnesium Sulfate as a Technique of Hypotensive Anesthesia during Functional Endoscopic Sinus Surgery. Egypt. J. Hosp. Med. 2019; 74 (8): 1759-1768.

5. Aremu PA, Ajayi AM, Ben-Azu B, Orewole OT, Umukoro S. Spinal and general anesthesia produces differential effects on oxidative stress and inflammatory cytokines in orthopedic patients [published online ahead of print, 2020 Oct 7]. Drug Metab Pers Ther. 2020;/j/dmdi.ahead-ofprint/dmdi-2020-0134/dmdi-2020-0134.xml.

6. Kundović SA, Rašić D, Popović L, Peraica M, Črnjar K. Oxidative stress under general intravenous and inhalation anaesthesia. Arh Hig Rada Toksikol. 2020;71(3):169-177.

7. Brattwall M, Warrén-Stomberg M, Hesselvik F, Jakobsson J. Brief review: theory and practice of minimal fresh gas flow anesthesia. Can J Anaesth. 2012;59(8):785-797.

8. March PA, Muir WW. Bispectral analysis of the electroencephalogram: a review of its development and use in anesthesia. Vet Anaesth Analg. 2005; 32(5):241-255 
9. Erel O, Neselioglu S. A novel and automated assay for thiol/disulphide homeostasis. Clin Biochem. 2014;47(18):326-332.

10.Bar-Or D, Lau E, Winkler JV. A novel assay for cobalt-albumin binding and its potential as a marker for myocardial ischemia-a preliminary report. J Emerg Med. 2000;19(4):311-315.

11.Jiang J, Zhou R, Li B, Xue F. Is deliberate hypotension a safe technique for orthopedic surgery?: a systematic review and meta-analysis of parallel randomized controlled trials. J Orthop Surg Res. 2019;14(1):409.

12.Barak M, Yoav L, Abu el-Naaj I. Hypotensive anesthesia versus normotensive anesthesia during major maxillofacial surgery: a review of the literature. Scientific World Journal. 2015;2015:480728.

13.Stevens JL, Feelisch M, Martin DS. Perioperative Oxidative Stress: The Unseen Enemy. Anesth Analg. 2019;129(6):1749-1760.

14.Bito H. "Metabolism and toxicity of anesthetics," Masui. The Japanese Journal of Anesthesiology, 1999; 48:172-179.

15.Song BC, Joo NS, Aldini G, Yeum KJ. Biological functions of histidine-dipeptides and metabolic syndrome. Nutr Res Pract. 2014;8(1):3-10.

16. Sanders LH, Timothy Greenamyre J. Oxidative damage to macromolecules in human Parkinson disease and the rotenone model. Free Radic Biol Med. 2013;62:111-120.

17.Wilson JX, Gelb AW. Free radicals, antioxidants, and neurologic injury: possible relationship to cerebral protection by anesthetics. J Neurosurg Anesthesiol. 2002;14(1):66-79.

18.Kevin LG, Novalija E, Stowe DF. Reactive oxygen species as mediators of cardiac injury and protection: the relevance to anesthesia practice. Anesth Analg. 2005;101(5):1275-1287.

19.Allaouchiche B, Debon R, Goudable J, Chassard D, Duflo F. Oxidative stress status during exposure to propofol, sevoflurane and desflurane. Anesth Analg. 2001;93(4):981-985.

20.Kotani N, Takahashi S, Sessler DI, Hashiba E, Kubota T, Hashimoto H, et al. Volatile anesthetics augment expression of proinflammatory cytokines in rat alveolar macrophages during mechanical ventilation. Anesthesiology. 1999;91(1):187-197.

21.Taşkın D, Gedik E, Kayhan Z. Effects of Minimal Flow Sevoflurane or Desflurane Anaesthesia on Hemodynamic Parameters, Body Temperature and Anaesthetic Consumption. Turk J Anaesthesiol Reanim. 2020;48(5):356-363.
22. Ceylan A, Kırdemir P, Kabalak A, Aksu C, Baydar M, Goguş N. Comparison of arterial carboxyhemoglobin, heamodynamic and recovery characteristics of low flow desflurane and sevoflurane anesthesia [Turkish Article]. Gulhane Medical J 2004; 46: 291-7.

23. Baum JA. Low-flow anesthesia: theory, practice, technical preconditions, advantages, and foreign gas accumulation. J Anesth. 1999;13(3):166-174.

24.Kilic F, Avci O, Duger C, Isbir A.I, Ozdemir Kol, Kaygusuz K. et al. Evaluation of Low and High Flow Anesthesia Methods Effects on Perioperative Hemodynamics, Depth of Anesthesia and Postoperative Recovery in Patients Unadergoing Abdominal Surgery. J Anesth Surg 2018; 5(1): 41- 47

25.Jena I, Nayak SR, Behera S, Singh B, Ray S, Jena D. et al. Evaluation of ischemia-modified albumin, oxidative stress, and antioxidant status in acute ischemic stroke patients. J Nat Sci Biol Med. 2017;8(1):110-113.

26.Roy D, Quiles J, Gaze DC, Collinson P, Kaski JC, Baxter GF. Role of reactive oxygen species on the formation of the novel diagnostic marker ischaemia modified albumin. Heart. 2006;92:1134.

27. Sonmez MG, Kozanhan B, Deniz CD, Goger YE, Kilinc MT, Neselioglu S. et al. Is oxidative stress measured by thiol/disulphide homeostasis status associated with prostate adenocarcinoma? Cent Eur J Immunol. 2018;43(2):174-179. 